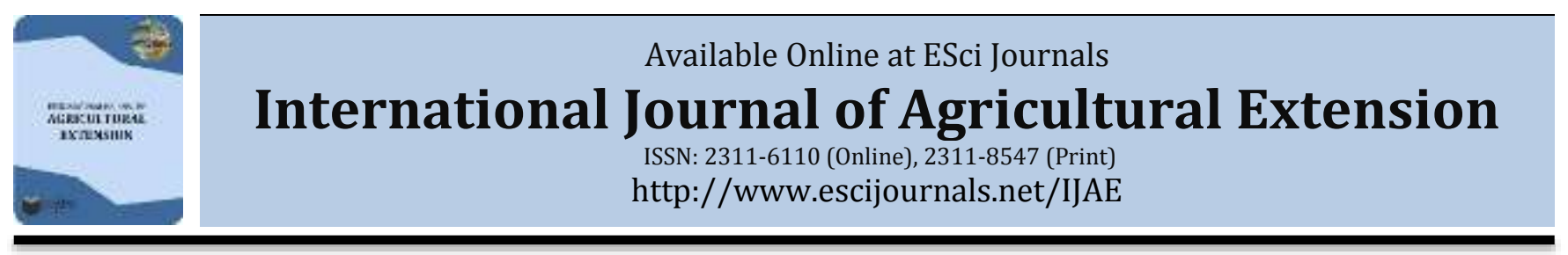

\title{
ASSESSMENT OF SKILLS GAP AMONG INTERMEDIARIES OF COTTON SUPPLY CHAIN IN PUNJAB, PAKISTAN
}

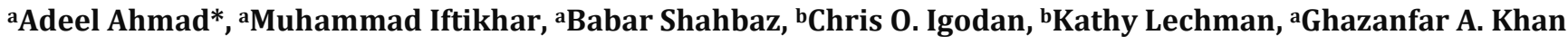 \\ ${ }^{a}$ Institute of Agricultural Extension and Rural Development, University of Agriculture Faisalabad, Pakistan. \\ ${ }^{b}$ Ohio State University, Columbus, Ohio, United States.
}

\begin{abstract}
A B S T R A C T
Cotton is an important crop in Pakistan as it contributes 1.0\% of GDP and 5.1\% in agricultural value addition (GOP, 2017). Despite the fact that cotton value chain has strategic importance in Pakistan in terms of its contributions towards GDP, employment, export earnings, poverty alleviation, and empowerment of women, its real value has not yet been realized. One area that has an effect on the income of farmers and that has not received attention is the role of middleman in agricultural marketing. The aims of this study were to address the skill gap of the commission agents and to develop techniques to bridge those gaps. Random sampling technique was used to determine sample size. The total sample size of the study was 50 respondents. SPSS (Statistical Package for Social Sciences) was employed to analyze the collected data. Results show that most of the respondents were in their productive ages to make effective decisions and understand the features of doing business. Of the total respondents, $6 \%$ had no education while $94 \%$ had the education of varied level. Respondents were experienced in doing the business of cotton marketing. Most of the commission agents were having an awareness gap regarding the quality characteristics of cotton. Commission agents had moderate skills level in management of various marketing costs. Mostly the commission agents were not considering fibre fineness, fibre length, fibre strength, fibre maturity and contamination due to hair as factors towards low prices and poor quality of cotton. Weak capacity of institutional infrastructure and lack of marketing system was the major constraint in the marketing of cotton. Commission agents should be equipped with training regarding maintenance of quality attributes, management of marketing costs and controlling of various factors affecting price and quality of cotton.
\end{abstract}

Keywords: Intermediaries, cotton, skill gap, marketing.

\section{INTRODUCTION}

Cotton contributes $1.0 \%$ to GDP of Pakistan and $5.1 \%$ in agricultural value addition (GOP, 2017). Of the total production of cotton in Pakistan, 81.0\% come from Punjab province and $19.0 \%$ from Sindh province (Government of Pakistan, 2003). Nationwide, greater than one fourth $(26.0 \%)$ farmers cultivate cotton on $15.0 \%$ of the total cultivated area and earns $54.0 \%$ of foreign exchange to sustain their livelihoods (Sabir et al., 2011; Government of Pakistan, 2009). In addition, the cotton seed is turned to edible oil and animals feed. Pertinent to multifaceted benefits of cotton crop and involvement of a major chunk of farmers in cultivation

\footnotetext{
* Corresponding Author:

Email: adeelformnite@gmail.com

(C) 2018 ESci Journals Publishing. All rights reserved.
}

cements its vital importance in balancing livelihoods and strengthen and alleviate poverty (Cororaton \& Orden, 2008). The cotton value chain is strategically important for Pakistan in terms of its contributions in GDP, employment, export earnings, poverty alleviation, and women empowerment, though the full potential of this majestic crop is still unexplored in the country. A comprehensive development in the value chain to make it globally competitive is the need of the hour. Production practices, ginning process, marketing mechanism, printing, stitching, machinery maintenance, factory floor performance, superior technology, research \& innovation are the areas need to be recovered and improved in Pakistan according to the global standards (Government of Pakistan, 2008). The Medium Term Development Framework (MTDF) 2005-10, of the 
Government of Pakistan, has documented an urgency to escape from inadequate skills on part of different stakeholders to develop balanced profit generating mechanism (Planning Commission, 2005).

Intermediaries have an important role in the cotton value chain and have an impact on growers' income and profits. For instance, the role of middleman in this regard cannot be undermined. This middleman not only markets the produce of growers but also helps them to access different inputs through financial facilitation. Conversely, the role of middleman faces criticism as well for the monopoly and influencing the market to raise his margin of benefits (Quartey et al., 2012). Once the cotton is picked, it is shifted to ginning factories for further processing and commission agents are the key determinants to link growers with the ginning industry. Having adequate skills of quality assessment, management of labour and grading skills would enable commission agents to perform their function in an effective manner. Role of intermediaries in cotton marketing cannot be ignored. However, research on intermediaries in Pakistan is scanty. Mapping the role of these intermediaries could be more useful to streamline cotton marketing system and implement regulatory measures. Therefore, this study was conducted to assess the skills gap of intermediaries of the cotton supply chain in the Punjab province. The findings of this study will be a good contribution to the scientific literature on intermediaries.

\section{METHODOLOGY}

Punjab province of Pakistan comprises of thirty-six districts and Bahawalnagar is one of those districts. The southern part of the province is comparatively warmer and conducive for cotton cultivation. This study was conducted in purposively selected district Bahawalnagar which is further subdivided into five tehsils (subdistrict) named as Bahawalnagar, Chishtian, Haroonabad, Fort Abbas and Minchinabad. A preliminary survey was conducted to prepare the list of commission agents in the district. This list served as the sampling frame and a foundation to go for random selection. From each tehsil 10 commission agents were selected, thereby making a total sample size of 50 commission agents. The questionnaire was used as research instrument. The questionnaire was prepared according to the objectives of the study. Prior final data collection, a questionnaire was pre-tested on 10 commission agents other than sampled commission agents. Content and face validity of the instrument was determined with the consultation of a panel of experts which included two Professors and two Assistant Professors from the Institute of Agri. Extension and Rural Development and one Associate Professor from the Department of Agricultural Marketing and Business, University of Agriculture Faisalabad. The questionnaire was administered through face to face interview technique. The collected data were analyzed through the Statistical Package for Social Sciences (SPSS). Descriptive statistics like frequency, mean, standard deviation and percentages were determined for the illustration of data. Skills gap was determined by subtracting obtained mean value from the 5 . Five refers to the 5 points Likert scale which was used to assess the extent.

\section{RESULTS AND DISCUSSION}

Table 1. Demographic Characteristics of Commission Agents.

\begin{tabular}{|c|c|c|}
\hline Demographic attributes & Frequency & Percentage (\%) \\
\hline \multicolumn{3}{|c|}{ Age } \\
\hline Up to 25 & 5 & 10.00 \\
\hline $26-35$ & 16 & 32.00 \\
\hline $36-45$ & 17 & 34.00 \\
\hline $46-55$ & 8 & 16.00 \\
\hline Above 55 & 4 & 8.00 \\
\hline \multicolumn{3}{|c|}{ Education } \\
\hline Illiterate & 3 & 6.00 \\
\hline Primary & 7 & 14.00 \\
\hline Middle & 9 & 18.00 \\
\hline Metric & 16 & 32.00 \\
\hline Intermediate & 8 & 16.00 \\
\hline Bachelors & 4 & 8.00 \\
\hline
\end{tabular}


Int. J. Agr. Ext. 6(3). 2018. 186-191.

\begin{tabular}{|c|c|c|}
\hline Masters & 2 & 4.00 \\
\hline Above & 1 & 2.00 \\
\hline \multicolumn{3}{|c|}{ Business Experience (Years) } \\
\hline Less than 5 & 8 & 16.00 \\
\hline $5-10$ & 14 & 28.00 \\
\hline $11-15$ & 13 & 26.00 \\
\hline $16-20$ & 8 & 16.00 \\
\hline Above 20 & 7 & 14.00 \\
\hline
\end{tabular}

Demographic Characteristics of Commission Agents: Data depicted in Table 1 illustrates that about $34.00 \%$ of the respondents fell in the age bracket of 36-45 years. One in ten respondents fell under the age of fewer than 25 years. About $8 \%$ respondents fell in the age bracket of more than 55 years. This implies that most of the respondents were in their productive ages to make effective decisions and understand the features of doing business. Of the total respondents, $6 \%$ had no education while $94 \%$ had the formal education of different level. About 14, 18, 32, 16.8 and $6 \%$ had a primary, middle matriculation, intermediate, bachelors and masters level of education respectively. Results further augmented that respondents were experienced in doing the business of cotton marketing. More than one-fourth respondents (28\%) had an experience of 5-10 years while $14 \%$ of respondents had experience of more than
20 years. This vast experiences certitudes that respondents had a clear understanding of cotton marketing. Results summarize that productive ages of respondents, satisfactory educational status and vast experience turned their business of cotton marketing in favour and productive for them.

Awareness regarding Quality Attributes of Cotton: Quality attributes of the cotton are imperative in grabbing higher rates. On part of commission agents, being aware and having a tendency to assess the quality of attributes is of great worth. Considering the importance, on the state-level government of Pakistan has induced quality considerations in the marketing system and has introduced a grading system for cotton (Malik, 2003). Thus, respondents were asked to unveil their awareness regarding the quality attributes of the cotton. Results are presented in Table 2.

Table 2. Awareness Level of Commission Agents regarding Assessment of Quality Attributes of Cotton

\begin{tabular}{|c|c|c|c|c|}
\hline Quality Attributes of Cotton & Weighted Score & Possessed Awareness & Awareness gap & Standard Deviation \\
\hline Fiber length & 110 & 2.20 & 2.80 & 0.85 \\
\hline Fiber strength & 68 & 1.36 & 3.64 & 0.66 \\
\hline Fiber fineness & 77 & 1.54 & 3.46 & 0.64 \\
\hline Color & 117 & 2.74 & 2.26 & 0.91 \\
\hline Trash & 139 & 2.78 & 2.22 & 0.73 \\
\hline Fiber maturity & 85 & 1.70 & 3.30 & 0.93 \\
\hline Hygroscopicity & 63 & 1.26 & 3.74 & 0.44 \\
\hline Elasticity & 73 & 1.46 & 3.54 & 0.70 \\
\hline Mean awareness gap & & & 3.12 & 0.732 \\
\hline \multicolumn{2}{|c|}{$\begin{array}{l}\text { Data depicted in Table } 2 \text { affirm that average awareness } \\
\text { gap among respondents was of slightly greater than } \\
\text { medium level }(X=3.12) \text {. This reflects that respondents } \\
\text { were not fully aware of cotton quality assessment. The } \\
\text { highest awareness gap was found regarding } \\
\text { "hygroscopicity" (X=3.74) followed by fibre strength } \\
(X=3.64) \text { and elasticity ( } X=3.54) \text {. This implies that } \\
\text { awareness gap regarding these attributes was more than } \\
\text { of medium level and heading towards high level. } \\
\text { Another quality attribute, fibre fineness }(X=3.46) \text { and }\end{array}$} & \multicolumn{3}{|c|}{$\begin{array}{l}\text { fibre maturity }(\mathrm{X}=3.30) \text { exhibited an awareness gap of } \\
\text { more than medium level as well. } \\
\text { The lowest awareness gap was calculated regarding the } \\
\text { assessment of trash contents }(\mathrm{X}=2.22) \text { followed by } \\
\text { colour }(\mathrm{X}=2.26) \text { and fibre length }(\mathrm{X}=2.80) \text {. This implies } \\
\text { that the awareness level of respondents regarding these } \\
\text { attributes was comparatively higher. This may further } \\
\text { imply that due to this extensive awareness gap, the } \\
\text { commission agents were not able to generate a targeted } \\
\text { outcome. }\end{array}$} \\
\hline
\end{tabular}


Skills Level of Commission Agents regarding Management of Marketing Costs: There are different marketing costs which are covered by the commission agents. Enhanced skills level of the commission agent regarding management of marketing costs may result in Table 3. Skills Level of Commission Agents regarding Management of Marketing Costs.

\begin{tabular}{lcccc}
\hline Marketing Costs & Weighted Score & Possessed Skill Level & Required Skill Level & Standard Deviation \\
\hline Grading & 97 & 1.94 & 3.06 & 0.71 \\
Packing & 125 & 2.50 & 2.50 & 0.73 \\
Store rent & 168 & 3.36 & 1.64 & 1.24 \\
Losses & 161 & 3.22 & 1.78 & 1.16 \\
Transport Expenses & 167 & 3.44 & 1.56 & 1.20 \\
\hline Average skills gap & & & 2.108 & 1.008
\end{tabular}

The average skills gap among respondents was of slightly higher than low level ( $\mathrm{X}=2.10)$ (Table 3). Among Grading skill had highest skill gap $(X=3.06)$. While packing showed skill gap of less than medium level $(X=2.50)$. These results are similar to those of Aslam (2010) where they reported the skill gap of medium level among respondents. In another study, Tegegne (2008) had reported that most of the respondents had a lower skill level regarding management of grading and packing costs.

Table 4. Factors Responsible for Low Price and Poor Quality.

\begin{tabular}{lccc}
\hline Factors & Weighted Score & Mean & Standard Deviation \\
\hline Fiber color & 156 & 3.12 & 1.11 \\
Fiber length & 81 & 1.62 & 0.63 \\
Fiber strength & 79 & 1.58 & 0.57 \\
Fiber maturity & 85 & 1.70 & 0.64 \\
Fiber fineness & 77 & 1.54 & 0.57 \\
Contamination due to trash contents & 155 & 3.10 & 0.73 \\
Contamination due to plastic bags & 124 & 2.48 & 0.64 \\
Contamination due to weeds and leaves & 121 & 2.46 & 0.61 \\
Contamination due to dupatta (cloth) & 136 & 2.72 & 0.72 \\
Contamination due to human hair & 80 & 1.60 & 0.72 \\
Storage & 110 & 2.20 & 0.75 \\
High moisture contents & 102 & 2.04 & 0.85 \\
Variation in moisture contents & 122 & 2.47 & 0.62 \\
The initial temperature of the seed cotton & 124 & 2.48 & 0.63 \\
The temperature of the seed cotton during storage & 109 & 2.18 & 0.71 \\
Weather factors during storage & 97 & 1.94 & 0.68
\end{tabular}

Data given in Table 4 reflects that fibre colour, contamination due to trash contents were the prominent factors hampering the quality. Fibre colour was perceived 1st factor $(X=3.12)$ while contamination due to trash contents was a second leading factor $(X=3.12)$. Respondents were of the view that contamination in higher returns to them. Based upon the collected data regarding skills level of the respondents regarding the management of different marketing costs, weighted score possessed level, required level and SD were calculated which are depicted in Table 3.
Perceived Factors Responsible for Low Price and Poor Quality: Different factors including fibre colour, fibre length, and fibre strength, contamination due to different sources and moisture contents quality and pricing of the cotton. The increased awareness level of quality attributes among commission agents may harness higher returns for them. Considering this importance respondents were asked to unveil their perceived factors affecting the quality and pricing of the cotton. picked cotton hampered marketing value significantly. The impact of these constraints was of slightly greater than medium level. This implies that if these factors are not considered carefully and managed timely, it may lower the quality, pricing value and net return for producers and different intermediaries. There were 
several other constraints perceived by the respondents which were lowering the quality. Among these factors, contamination due to cloth, plastic bags, moisture variations and improper storage had a contribution to lowering the quality of cotton. However, fibre length, strength, maturity and fineness had the least contribution in impeding the quality of cotton. This implies that several cares are required to be taken at the time of picking. Avoiding contamination, proper storage and transportation can retain the value for growers in particular.

Constraints Faced by Commission Agents in Marketing of Cotton: There are several challenges involved in the marketing of cotton. Many loopholes are found in the present legislation and there is no organized and regulated marketing system for the marketing of cotton. Based upon the collected data regarding various constraints facing by the commission agent respondents, weighted score, mean, SD and ranks were calculated which are presented in Table 5.

Table 5. Constraints Faced by Commission Agents in Marketing of Cotton.

\begin{tabular}{lcccc}
\hline Constraints/Factors & Weighted Score & Mean & Standard deviation & Rank \\
\hline Weak capacity of institutional infrastructure & 189 & 3.78 & 0.79 & 1 \\
and lack of marketing system & & & & \\
Price fluctuations & 182 & 3.64 & 1.03 & 2 \\
Improper transportation & 179 & 3.58 & 0.89 & 3 \\
Improper storage & 168 & 3.35 & 0.76 & 4 \\
Weak cotton quality management system & 162 & 3.24 & 0.98 & 5 \\
Poor marketing conditions & 160 & 3.20 & 1.03 & 6 \\
Difficult procedure to get license & 159 & 3.18 & 0.84 & 7 \\
Lack of technical knowledge & 147 & 2.94 & 0.73 & 8 \\
Lack of resources & 146 & 2.92 & 0.94 & 9 \\
Lack of technical labor & 144 & 2.88 & 0.79 & 10 \\
Unavailability of cotton stores & 137 & 2.74 & 0.79 & 11 \\
Improper packing material & 131 & 2.62 & 0.82 & 12 \\
Lack of policies & 130 & 2.61 & 0.72 & 13 \\
Inability to compete with unlicensed traders & 129 & 2.60 & 1.04 & 14
\end{tabular}

Data mentioned in Table 5 illustrates different constraints faced by the commission agents in marketing cotton. Weak capacity of institutional infrastructure and lack of marketing system stood on 1st rank with a mean value of 3.78. Price fluctuation was a 2 nd leading challenge with a mean value of 3.64. During informal discussion respondents argued that crashed marketing system and erratic price of cotton affects the net return. On farmers' level, price fluctuation compels farmers to shrink cotton cultivation area and cultivate alternative crops. Quartey et al. (2012) had reported that price fluctuation and defective marketing system were leading challenges impeding the value of cotton. Improper transportation was a 3rd leading challenge faced by the respondents $(\mathrm{X}=3.58)$. Defective roads and improper mode of transportation cause quality reduction and contamination. The improper system of storage was perceived as another leading challenge with a mean value of 3.35. This augments that poor storage of cotton enhances moisture level and contamination of traces. During informal discussion, respondents were found formally aware of the proper storage system. Weak cotton quality management system was a 5th leading challenge with a mean value of 3.24. Lack of technical labour, non-availability of stores for storage of cotton, improper packing material, lack of policies and Inability to compete with unlicensed traders were the least challenges as perceived by the respondents.

\section{CONCLUSION AND RECOMMENDATIONS}

Most of the respondents were in their productive ages to make effective decisions and understand the features of doing business. Of the total respondents, $6 \%$ had no education while $94 \%$ had the education of varied level. Respondents were experienced in doing the business of cotton marketing. Most of the commission agents were having an awareness gap regarding quality characteristics of cotton and due to this gap, they are not able to control the quality of cotton. Commission agents had moderate skills level in management of various marketing costs. Mostly the commission agent respondents were not considering fibre fineness, fibre length, fibre strength, fibre maturity and contamination 
Int. J. Agr. Ext. 6(3). 2018. 186-191.

due to hair as factors towards low prices and poor quality of cotton. Weak capacity of institutional infrastructure and lack of marketing system were the major constraints in the marketing of cotton followed by price fluctuations and improper transportation. This study recommends that commission agents should be equipped with training regarding maintenance of cotton quality attributes, management of marketing costs and controlling of various factors affecting price and quality of cotton. There is an urgent need to restructure the marketing system of cotton and infrastructure of markets.

\section{REFERENCES}

Cororaton, C.B. \& D. Orden. (2008). Pakistan's Cotton and Textile Economy: Intersectoral Linkages and Effects on Rural and Urban Poverty. International Food Policy Research Institute.

Cronbach, L.J. (1951). Coefficient Alpha and the Internal Structure of Tests. Psychometrika, 16(3), 297334.

Government of Pakistan. (2003). Agricultural Marketing System in Punjab. Directorate of Agriculture. Government of Punjab, Lahore.

Government of Pakistan. (2008). Economic Survey of Pakistan. World Cotton Outlook, Agriculture. Islamabad, Finance Division.
Government of Pakistan. (2009). Agricultural Marketing System in Punjab. Directorate of Agriculture. Government of Punjab, Lahore.

Government of Pakistan. (2017). Economic Survey of Pakistan. Cotton Crop, Agriculture. Islamabad, Finance Division.

Malik, S. (2003). The Role of Mass Media in Diffusing Modern Agricultural Techniques in District Sheikhupura. M.Sc. (Hons.) Thesis. Department of Rural Sociology, University of Agriculture, Faisalabad, Pakistan.

Planning Commission. (2005). Planning and Development Division, Government of Pakistan.

Quartey, P., C. Udry, S. Al-Hassan \& H. Seshi. (2012). The Role of Middlemen in Marketing and Credit Outcomes in GHANA. Agricultural Financing and Credit Constraints: International Growth Center.

Sabir, H.M., S.H. Tahir and M.B. Khan. (2011). Bt. Cotton and Its Impact on Cropping Pattern in Punjab, Pakistan. Pakistan Journal of Social Sciences, 31(1), 127-134.

Tegegne, B. (2008). Analysis of Cotton Marketing Chains: The Case of Metema Woreda, North Gondar Zone, Amhara National Regional State. M.Phil Thesis, College Of Agriculture, Department of Agricultural Economics, School of Graduate Studies Haramaya University. 